costs, are relatively insensitive to increases in the cost of fuel. Even at a fuel cost of $3 \cdot 25$ pence per therm, the CEGB argues that a coal fired station would cost $£ 1$ million a year more to run than a nuclear station. If Lord Robens wants to sell coal at 3.25 pence a therm, the CEGB will be only too happy to buy it, to replace much more costly coal it is already burning (see chart).

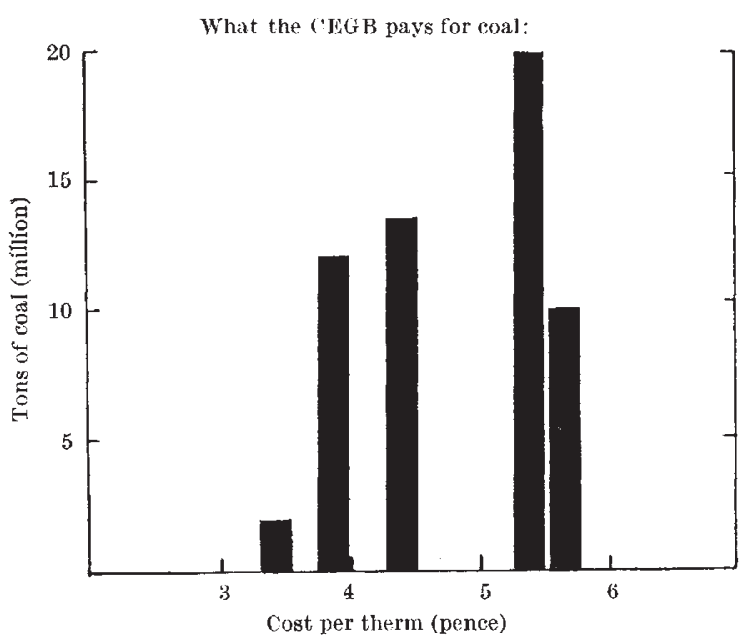

This is why the CEGB is in no mood to take Lord Robens's claims seriously. The great majority of power in Britain will continue to be generated by coal -even by 1972, over 70 per cent of the electricity will be generated by coal. The idea that Seaton Carew is a crucial test case which will determine the future of the coal industry is thus rather facile, if not misleading.

But Lord Robens has found some support from the House of Commons Public Accounts Committee. In its latest report, the committee is critical of the Atomic Energy Authority and the CEGB for the way in which the royalties payable on nuclear gencration have been fixed. For the original magnox stations, which were not expected to be competitive with other sources of power, no royalties were charged. For later magnox stations, which are competitive, it was decided in principle that royalties should be charged, but because of a disagreement between the AEA and the CEGB, the Treasury decided that the magnox royalties should be waived. Instead, the Treasury suggested that a royalty of 0.014 pence per unit of electricity sent out should be paid by the generating board for the AGR stations. The Public Accounts Committee calculates that even on the most optimistic basis possible, this rate of royalty will produce only $£ 26$ million on the present nuclear power programme. The AGR system, according to the AEA, will cost a total of $£ 110$ million to develop, so that the return on the present basis will be less than a quarter of the investment. The committee suggests that this low rate of royalty was in fact designed as an inducement to the CEGB to adopt the AGR, an inducement which it does not think should have been necessary. And in a passage which must have made the mining lobby cheerful, the PAC says that it is not convinced "that the extent to which the cost of generating electricity is being indirectly subsidized by the taxpayer is devoid of economic significance". Put plainly, the PAC thinks the public has been swindled.
The argument, of course, is put less crudely than this The difficulty is to say whether the balance of advantage should lie with the taxpayer or the electricity consumer, two groups which are not always identical. So far, as the PAC points out, the electricity consumer has been favoured. Much depends, of course, on how many more AGR stations are built, but the point is raised even more uncomfortably for the Steam Generating Heavy Water Reactor which the AEA has developed at considerable cost. Unless royalties for this type of reactor are set very much higher than those for the AGR, there seems little chance that the development costs will be recovered. And unless royalties are set at a fair level, it becomes impossible to assess the competing claims of different sources of power. This is playing into Lord Robens's hands.

\section{Eye on the Planets}

IN a revised report on recommended goals for the United States civil space programme after Apollo, the Space Sciences Board of the National Academy of Sciences and the National Research Council has this week (August 15) urged that the exploration of the planets should be given priority and "a substantially increased fraction of the total NASA budget". The present proportion-about 2 per cent of the total NASA budget-is described as "totally inadequate to take advantage of the opportunities available to us". But NASA's interim operating plan, prepared in the light of severe budget cuts this year and also just published, further diminishes what is left of the planetary programme-the Mariner mission to Mars in 1973.

In its 1965 report Space Research-Directions for the Future, the Space Sciences Board recommended that planetary exploration and in particular the search for life should be the main focus of the national space effort in the seventies. The Apollo Applications Programme (AAP) was adopted instead. Now even this has been cut down to two missions by the latest NASA plan, one Saturn I Workshop and one Apollo Telescope Mount. Production of Saturn I and Saturn $V$ vebicles is to stop. This means there will be an inevitable time gap in the programme if Congress later reviews its position. Rather less than half ( $\$ 140$ million) of the amount requested ( $\$ 300$ million) has been made available for AAP in the 1969 budget. The 1973 Mars mission is being sharply reduced in size and scope to match its reduced funds. The landing instrument package and its scientific return will be "substantially less" than originally envisaged in this year's approach to Congress. But the NASA efforts on Apollo, on space applications and on advanced aeronautics are virtually untouched.

In contrast, the Space Sciences Board wishes to see a diversion of funds from manned missions, and disagrees with proposals that the next major space goal should be to place a man on a planet, presumably Mars. Fully automated systems are developing so rapidly that probe technology should be capable of answering the major scientific questions that we can now pose about the planets without intervention on the spot by man. "While at some time in the future it may be in the national interest to undertake a manned programme to the planets, we do not believe man is essential for scientific planetary investigation at this stage." In 
this report the board confines itself to the period 1968-1975.

To put its views into practice, it recommends that relatively small and inexpensive unmanned spacecraft be launched to orbit Venus and Mars at each favourable conjunction (these occur at roughly 18-month intervals for Venus, and every 2 years for Mars). NASA should send spin-stabilized spacecraft of the reliable Pioneer and IMP types on planetary missions over the next 7 years, the board considers. It favours the diversion of existing Pioneer E craft to the exploration of Venus in 1970, with additional flights in 1972, 1973 and 1975. It also strongly supports a Pioneer mission to pass by Jupiter, the solar system's largest planet, in 1972 and 1973.

Because of the great importance of biological investigations of Mars, the report recommends a Mariner orbiter mission there in 1971, and a Marinercarried combination orbiter and lander in 1973. The proposed Mars missions and the small planetary spacecraft series are considered a "minimal programme"; but, the report asserts, "such a programme has greater priority both in terms of expected purely scientific returns and in long term benefits to society than other space ventures such as the qualifying of man for planetary voyages".

In both 1973 and 1975 a spacecraft on a fly-by mission to Venus could make use of the planet's gravitational field to be accelerated on to Mercury. Such an opportunity-which will not recur until the eightiesprompts the report to give second highest priority to this "two-for-one" mission. The fly-by would provide the first close photographs of Mercury and possibly reveal surface effects caused by the planet's proximity to the Sun. It will be interesting to see if the Space Sciences Board's new report has any more influence on the direction of the national programme than did the last one.

\section{Costly Phantom}

UNHAPPY decisions made by the Ministry of Aviation keep coming to light. Usually the Public Accounts Committee of the House of Commons has the sad task of publishing the details, and the latest report from the committee is no exception (HMSO, $£ 3$ 16s.). The committee investigated two decisions in particular; one, to buy a small number of Beagle Basset aircraft and the other to fit the Rolls-Royce Spey engine into the American Phantom aircraft.

When the Royal Navy decided to buy the Phantom, it was already quite an old aircraft. Nearly 3,000 had been produced in the United States, but the Royal Navy had to have a more powerful version to enable the aircraft to take off from the shorter British aircraft carriers. It was therefore decided to fit the Spey engine into the Phantom, at a tentative development cost of $£ 25$ million. By the time a firm decision was taken, the cost was up to $£ 34-39$ million, but the full costed programme was not produced by Rolls-Royce until after the decision had been taken in February 1965 to buy the Spey Phantom for the Royal Air Force as well. By May 1965, the cost of developing the engine and modifying the airframe to fit the engine and take British electronic equipment for the Navy and the RAF was up to $£ 80-90$ million. When the costs of production in Britain are taken into account, the total cost of the anglicized Phantom is about 50 per cent more than the American version, and the unit cost of the 170 Phantoms which are being bought is almost twice the cost of the American version. In contrast, when the Hercules aircraft was bought from the US, the price paid was almost exactly the same as that paid by the American armed forces, because no expensive modifications were demanded.

The committee draws the obvious conclusions from this sorry story. When off the shelf purchases are made, the report says, the benefit of reduced costs arising from long production runs can be totally lost if the standard version is substantially modified. Unfortunately, there is less evidence that the RAF has learned its lession. Before the cancellation of the FIll aircraft from the US, there were already signs that the cost of the aircraft was increasing because of RAF demands for British equipment to be installed.

The other PAC investigation tells an equally sad tale, which seems to have sprung from equally good intentions. In 1963 the RAF was persuaded by the Ministry of Aviation to buy a new aircraft, the Beagle Basset, in place of the slightly old-fashioned Devon. The role the Basset had to fill was for a communications aircraft and also as a transport for ferrying the crews of bombers about. But it soon became clear that the performance of the Basset was not all that had been hoped for; at high temperature there was a much greater decrease in engine power than had been expected. Although the RAF is prepared to accept safety standards lower than those acceptable for civil airlines, it became clear that either the payload or the range of the Basset was going to suffer. In fact, as the PAC found out, the Basset carrying five people has a range of 485 miles instead of 1,000 miles at $15^{\circ} \mathrm{C}$, and the seven seat version needed for transporting $V$ bomber crews has a reduced payload and a range reduced to 194 nautical miles at $15^{\circ} \mathrm{C}$. At $30^{\circ} \mathrm{C}$, the range of the seven seat version is reduced to nil, an unhappy situation for a $\mathrm{V}$ bomber crew stranded somewhere hot. In part this failure was caused by the requirement of the RAF for more equipment than is normal in civil airliners; and it seems that the extra 300 pounds of equipment reduce the range by about 300 miles. Nobody denies that the Devon would have been better, though marginally more expensive $(£ 73,000$ against $£ 65,000$ each), but the Ministry of Aviation seems to have been motivated by the laudable aim of encouraging the development of small aircraft in Britain. The Ministry of Technology, in fact, continues to support the Beagle company, without so far producing much visible return.

\section{Nuclear Gas}

IF preliminary results are any guide, Project Gasbuggy, the American experiment to increase the recovery of natural gas from rock formations of low permeability by fracturing the rock with a contained nuclear explosion, has been a success. The principle behind the experiment is, of course, well tried; the normal practice in mining gas from sandstone formations is to drill the well and then fracture the gas-bearing strata either by forcing water into the rock or, more rarely these days, by exploding nitroglycerine at the bottom of the shaft. Gasbuggy, a joint venture of the US Atomic Energy Commission, the Department of the 